\title{
Group (epistemic) competence
}

\section{Dani Pino' ${ }^{1}$}

Received: 31 October 2020 / Accepted: 30 June 2021 / Published online: 23 July 2021

() The Author(s) 2021

\begin{abstract}
In this paper, I present an account of group competence that is explicitly framed for cases of epistemic performances. According to it, we must consider group epistemic competence as the group agents' capacity to produce knowledge, and not the result of the summation of its individual members' competences to produce knowledge. Additionally, I contend that group competence must be understood in terms of group normative status. To introduce my view, I present Jesper Kallestrup's (Synthese 1-19, 2016) denial that group competence involves anything over and beyond the aggregation of individual competences. I have divided my response into two parts. First, I compare two conceptions of competence from Ernest Sosa's reliabilist virtue epistemology (Sosa in Philos Stud 142:5-15, 2009; Philos Perspect 24:465-475, 2010a; Knowing full well, Princeton University Press, 2010b; Judgment \& agency, Oxford University Press, 2015; Epistemology, Princeton University Press, 2017; in: Silva-Filho, Tateo (eds), Thinking about oneself: The place and value of reflection in philosophy and psychology, Springer, 2019) and David Löwenstein's (Knowhow as competence. A Rylean responsibilist account, Vittorio Klostermann, 2017) account of know-how. Second, I take the results from this comparison and apply them to the issue of group know-how, by the hand of Orestis Palermos and Deborah Tollefsen's twofold approach to the topic (Palermos and Tollefsen, in: Carter, Clark, Kallestrup, Palermos, Pritchard (eds) Socially extended epistemology, Oxford University Press, 2018). Finally, I return to Kallestrup's denial to make my point in favour of the conception of genuine group competence as the group normative status to achieve success.
\end{abstract}

Keywords Group knowledge · Virtue epistemology · Competence · Know-how · Group agency

\section{This article belongs to the topical collection "New Directions in Social Epistemology", edited by} Adam Carter and Christoph Kelp.

\section{Dani Pino}

dps@us.es

1 Universidad de Sevilla, Seville, Spain 


\section{Introduction}

The capacity of groups of individuals to perform actions is a well-known phenomenon in the literature. There are debates regarding whether this capacity results from aggregation (the summation of each member's capacity) or integration (the reflection of irreducible group properties). This picture parallels another debate which focuses on one particular outcome that results from action: the nature of group propositional knowledge. According to this debate, the main question at issue is whether we should consider group knowledge in terms of summativism (as the summation of each member's knowledge or the representation of the majority of the members' knowledge) or some form of non-summativism (as the result of group knowledge that is not reducible to its members' knowledge). The clarification of both debates requires further development of the agential properties involved in group knowledge. Jesper Kallestrup provides a recent approach to this issue. His account of group virtue epistemology (2016) focuses on one particular conception of group epistemology: Ernest Sosa's competence-based virtue reliabilism (2009, 2010a, 2010b, 2015, 2017, 2019). Kallestrup comes across a striking situation: although a group epistemic agent may produce group knowledge that is not reducible to its members' knowledge, the reliable competences that the group manifests to acquire such knowledge are simply the summation of the group's individual members' competences. In a nutshel: group knowledge is irreducibly collective, whereas competences in general, and epistemic competences in particular, are reducible to individual compenteces-how is this possible, if an agent's knowledge should result from the epistemic competences of the same agent and not others? He refers to this as "the crucial disanalogy".

In this paper, I will resolve Kallestrup's disanalogy in a different way by contending that a group epistemic agent may manifest competences that are not reducible, nor do they result from, the summation of its individual members' competences. Specifically, I maintain that group competence should be identified with the group's normative status.

This is the structure of the paper: In Sect. 2, I briefly describe the debates on rejectionionism about group belief in an attempt to focus on a less controversial approach that stems from the assumption of group epistemic agents. In Sect. 3, I focus on Kallestrup's crucial disanalogy, showing in detail how it emerges from Sosa's model on epistemic competences. This scenario motivates two questions. First, what is the nature of competence? Second, is the notion of competence bound to methodological individualism? Sect. 4 focuses on the first question by delving into the idea of performance and, in particular, the concept of skilled performance. I do so by comparing Ernest Sosa and David Löwenstein's conceptions of competence, aiming to show that both approaches share a common core assumption: an agent's manifestation of reliable competence to achieve a specific goal indicates that a set of norms guides the agent's performance which, on the one hand, regulates the agent's activity and, on the other hand, are properly understood by the agent as a guide to performing well. Then I address the second question, and for this purpose, I compare this account of competence with group 
agency by drawing on Orestis Palermos and Deborah Tollefsen's joint approach to group know-how. According to this approach, group agents may be deemed as knowing-how to act from two perspectives: one intellectualist and the other anti-intellectualis. Thus, in Sect. 5, I return to Kallestrup's denial of robust group competence to confront it by appealing to this new account of competence based on methodological anti-individualism. Finally, I present an account of a group agent whose normative status instantiates its epistemic competence.

\section{Group knowledge}

Epistemic life is not only exhibited by individuals. A research team that publishes a paper contending a new approach to a particular question, a jury that renders a verdict or a management board that evaluates the last year's financial results all depict situations in which a collection of individuals is subject to epistemic attributions. Accordingly, the individuals themselves are not subject to such attributions; instead, it is the group who is subject to them. In other words, these situations depict groups acting as a whole entity to produce an epistemic outcome. Furthermore, what does "as a whole entity" mean? The battle begins here. Summativists hold that a group possesses a property (such as an epistemic or doxastic property) if, and only if, all or the majority of its members have this property (Quinton, 1976). In contrast, Nonsummativists hold that some groups may feature purely collective properties that cannot be traced back to its members, being considered as mere individuals.

\subsection{Group belief}

Different conceptions of non-summativism have emerged; however, they seem to differ regarding the role of belief. Some people, known as believers, consider group beliefs to be unproblematic and hold that group beliefs are the basis of group knowledge (or group epistemic competence). Margaret Gilber's acceptance account is responsible for one of the most influential branches of this view, which states that a group may be a genuine bearer of a collective belief $p$ in so far as it results from the members' joint commitment to accept $p$ as a body (Gilbert, 1987, 2002, 2004).

However, others reject this view-those known as rejectionists - and hold instead that joint commitment does not yield group belief, but rather group acceptance (Hakli, 2007; Meijers, 2002; Wray, 2001). Rejectionists motivate their view by stating that beliefs have distinctive features that acceptance does not, such as non-voluntariness, ${ }^{1}$ gradability or context dependence, among others (Preyer, 2003). Believers

\footnotetext{
1 Regarding the issue of voluntariness, Tuomela avoids thinking of acceptance as a necessary condition. According to his view, «acceptance "typically" is an intentional mental acceptance, but it need not always be. As non-intentional acceptance, it clearly seems possible that a person come to accept that there is a tree in front of him without doing this at will or on purpose. As a matter of psychological fact, if it indeed is one, this acceptance is normally based on the person's causally induced belief that there is a tree in front of him. Given this, the acceptance involves reflection on one's belief (or beliefs) without yet being a mental action performed on purpose» (2000a, p. 125).
} 
have struck this view back by adopting alternatives to the joint acceptance account (Tuomela, 1995, 2007; Tollefsen, 2003). Some other approaches opted to dodge the bullet of group belief in terms of typically mental states hosted in an individual's mind by appealing to a functional distribution of epistemic tasks (Bird, 2010), group agency as group rationality (List \& Pettit, 2011; Pettit, 2007; Tollefsen, 2004), and group cognition in terms of dynamical systems (Palermos, 2016; Palermos \& Pritchard, 2016). More recently, a new line of contributions has returned to Hakli's (2007) possibility of group knowledge without group belief, but with alternative ways, such as knowledge-first collective epistemology (Simion et al., 2020) or collective telic epistemology based on apt judgmental knowledge (Carter, 2020). ${ }^{2}$

\subsection{Group epistemic agency}

As mentioned, both believers and rejectionists share the assumption that group attributions of knowledge fit into a non-summativist framework. Thus, if group properties happen to be somewhat controversial to break down in terms of beliefwhere the belief is a necessary condition for the traditional conception of knowledge-switching to agential properties may stand as a good alternative. In fact, it is because the mere summation of each members' contributions-through individually considered endorsements or acceptances-does not accurately explain how the group comes to know that group epistemic agency poses an appealing framework to start coping with the phenomenon of group or collective knowledge. ${ }^{3}$ However, it leads back to the old problem of summativism: why should we contemplate group epistemic agents when it is more intuitive to consider a set of individual epistemic agents that interrelate with each other following specific patterns? We may then answer by saying that, ultimately, it is because there might be significant divergence between the individual epistemic states of the group members and the collective epistemic states of the group considered as a whole entity. The so-called discursive dilemma (List \& Pettit, 2004, p. 213; 2011, Ch. 2) eloquently depicts such scenarios. According to the discursive dilemma, a group may deliberately attempt to produce an epistemic outcome $p$ that happens to diverge from the aggregation of the majority of the individual beliefs as shown in the following Table 1.

This representation of the dilemma shows a situation in which the aggregation of attitudes regarding pieces of evidence one and two (bottom-up) provides the group

\footnotetext{
${ }^{2}$ Despite the similarities between Carter's approach and the one I support in this paper-especially regarding Kallestrup's view on the crucial disanalogy between group knowledge and group competence (2020, p. 5242) - my proposal elaborates on competences as opposed to knowledge-although it is due to the manifestation of the former that makes it possible to achieve the later.

3 In Kay Mathiesen's words, «work on "agent centered" epistemology should focus on groups as well as individuals» (2011, p. 23). That is, in so far as we accept that knowledge stems from the performance of certain kinds of action-say, cognitive or epistemic actions-we are pushed to accept that the scale for specific cases of group or collective knowledge exceeds the individual level when accounting for them. However, when it comes to contend whether groups may form or hold beliefs, she rather takes groups as pragmatic agents rather than epistemic agents (2006).
} 
with its own collective attitudes, ${ }^{4}$ whilst the application of a rule of rationality, specifically the conjunction rule (left-to-right), yields each epistemic agent's composed attitude $E 1 \& E 2$, or $p$, that aims at knowledge. Then, how is the group attitude that comprises $p$ formed? According to Tollefsen (2004, p. 58), overcoming the dilemma is a matter of how we are driven towards it. In the case that we opt for a conclusion-driven approach, we would be following the first strategy in order to obtain the collective attitude, so the group would deem E1\&E2 to be a false conjunction, and therefore not- $p$. However, it seems quite odd, in so far as the group, as an agent, would be then cognitively acting against the rule of rationality that is involved in the second strategy - which is followed by the individual agents though. After all, the application of the conjunction rule conducts each member towards her respective conclusions regarding $p$. Hence, Tollefsen opts for a premise-driven approach-that is, following the conjunction rule to bring about the group attitude $p$-to preserve the rationality of the group agent, hence suppressing the divergence between these two-level attitudes. So considered, we should not be tempted to see three epistemic agents and a group, but four epistemic agents, three of which co-operate in the initiation of the group functioning as a whole entity.

In turn, Kallestrup (2020, p. 5239) provides a slightly different prospect for approaching divergence. Let us take a jury of seven in a criminal court that is judging a defendant. During the trial, all the jurors are presented with evidence from the police report and a piece of testimony, both suggesting the defendant's liability. However, the judge prompts the jury to ignore this information when rendering the verdict, since the evidence is not beyond a reasonable doubt and because, in her opinion, the testimony is not sufficiently reliable. Accordingly, the jury, as a whole, finds the defendant innocent, even though each juror, as an individual, thinks of the defendant as guilty after consideration of both the evidence and the testimony. ${ }^{5}$

The epistemic divergence shown by both the discursive dilemma and Kallestrup's case leads us to think of the group as an entity of its own whose epistemic activity meets similar, if not straightforwardly equal, requirements as those of individual agents: collective acts just like individual acts in situations in which the performance towards knowledge is governed by the same standards that frame the attributions of epistemic states (Tollefsen, 2015, Ch. 5). So what is the problem? To answer this question, we need to make a detour through Ernest Sosa's reliabilist virtue epistemology in Sect. 3. In essence, Sosa holds that knowledge results from the manifestation of an agent's competent epistemic action. In terms of group agency, this increases the gap between collective competences and collective knowledge. Just like Kallestrup highlights, despite group knowledge attributions are not reducible to each member's knowledge, group competence seems to be nothing more than the

\footnotetext{
4 The aggregation of attitudes works in this framework as a consensus rule, that is, a majority rule that functions just as summativists hold.

5 In his paper, Kallestrup confronts this case (criminal court) with a subtle variation of it (civil court) by which he emphasizes the divergence between individual and group attitudes. However, I find that drawing solely on the first case makes it clear enough for the purposes of this paper.
} 
Table 1 The discursive dilemma

\begin{tabular}{llll}
\hline & Evidence 1 & Evidence 2 & E1\&E2 $=p$ \\
\hline Member 1 & True & True & True \\
Member 2 & True & False & False \\
Member 3 & False & True & False \\
Group & True & True & $¿ ?$ \\
\hline
\end{tabular}

aggregation of individual competences, giving rise to what he labels as the crucial disanalogy.

In this section I have claimed that an agential approach to the problem of group knowledge could be helpful in order to avoid the difficulties of accounting for group belief. I have presented the agential approach with the help of List and Pettit's discursive dilemma, and then I have introduced the disanalogy that Kallestrup appreciates between the group knowledge and group competence. My goal in the next section is to elucidate this alleged disanalogy and to elaborate Kallestrup's motivation for it.

\section{The crucial disanalogy}

First of all, as previously mentioned, the disanalogy makes sense in so far as we adopt Ernest Sosa's (2010a, 2010b, 2015) reliabilist or competence ${ }^{6}$ virtue epistemology approach. According to this approach, a true belief amounts to knowledge when it is true because it is apt. Moreover, what determines the aptness of a belief? Its accuracy, that is, the way the cognitive performance of a given agent aims at a goal - a true belief that amounts to knowledge, in the case of epistemic actionsbeing accurate in so far as it is adroit. Thus, knowledge, as apt belief, is seen as a cognitive achievement that results from the agent's adroitness to perform cognitively well, bringing about apt beliefs. Additionally, this triple-A (aptness, accuracy, adroitness) analysis of knowledge comes along with a triple-S analysis of the competences that constitute the adroitness of the epistemic agent when aiming at success - that is, avoiding cases of luck or mere chance. According to this analysis, for an agent to manifest a complete competence, this competence must meet three components. First, there is the innermost competence, or the seat, that hosts the skill or disposition of the agent required for her to perform a given activity. Someone with the ability to drive a car would be said to have the innermost competence or skill of driving. Second, this innermost competence, or seat, must be present in combination with the inner competence, or the shape, that frames the agent's performance. Our driver may be in an adverse state while driving, perhaps drunk or sleepy; therefore, despite having the innermost competence of driving, she fails in adopting the proper shape to engage in that action. Third, even a skilled agent in proper shape might

\footnotetext{
${ }^{6}$ Sosa considers both tags to be interchangeable in (2015, p. 36).
} 
perform a given action in adverse circumstances, like driving in hard rain or over an oiled road. The situation is, therefore, a necessary component that must also be met to manifest the complete competence to do something.

\subsection{Summativist competences vs Non-summativist knowledge}

With Sosa's triple-A and triple-S analyses in mind, Kallestrup concludes that even if a group agent may yield knowledge under the "apt belief" schema and knowledge is not the result of the summation of the group members' knowledge but genuinely collective knowledge, group competence is not equally irreducible. Contrary to that, group competence results from the combined competences of its members. Kallestrup presents the disanalogy in the following terms:

On the one hand, a group's innermost competence is reducible to a summation of innermost competences of its individual members and their manner of arrangement within the group. Of course, a group may have innermost competences that none of its individual members have in isolation, but that's compatible with the former being reducible to the totality of individual innermost competences, given how they are brought to bear within the group. Novel competences of groups do not spring into existence or mysteriously emerge when conjoining existing individual ones. On the other hand, the aptness of group belief is not similarly reducible to the aptness of the beliefs of its individual members. [I]t's possible for the aptness of group belief to diverge from the aptness of a majority of, or indeed every single, individual belief, and so there is no question of the former being captured by a summation of the latter. Reasons for the disanalogy include that a group's innermost competence can produce the truth of its belief even though no individual beliefs are even formed, and that the shape and situation that are suitable for a group's innermost competence to produce the truth of its belief differ from the shape and situation that are suitable for the individual innermost competences to produce the truths of individual beliefs. Thus, there are various ways in which a group can be such that the truth of its belief manifests competence, its innermost competence is nothing over and above the joint innermost competences of its individual members, yet the truth of its belief manifesting competence does not consist in the truths of its members' beliefs manifesting their competences. (2020, p. 5242)

How does this picture fit in cases of group epistemic agency such as the discursive dilemma? Let us take the example of the discursive dilemma. Kallestrup's diagnosis does not go against the claim that the group epistemic outcome ( $p=$ true) is irreducible to its members' epistemic outcomes. Contrary to that, he stresses the disanalogy because, on the one hand, group knowledge may be irreducible to individual knowledge and, on the other hand, it is the individual members' competence which is to be manifested in order to achieve that group knowledge. In his view, the group has no "innermost competences over and above the joint innermost competences of its individual members". Thus, the problem lies in how to proceed in behalf of an account 
of group competence when the collective apt belief that amounts to knowledge does not seem to be due to any other competence than those that are individually seated in each member. Kallestrup is willing to accept that a group may have a competence that none of its members has, although his acceptance relies upon the idea that this group competence is, as mentioned, 'nothing over and above the summation or combination of the individual members'. Moreover, and this is very important, he does not constrain the group competence to the summation of individual competences, but considers its arrangement within the group, which is related to its internal organisation.

\subsection{The first defence of group epistemic competence}

In order to avoid the disanalogy, I envisage group organisation consisting of three steps that can be identified in the discursive dilemma as depited in Table 1 (Sect. 2.2). First, each individual member evaluates both pieces of evidence $E 1$ and $E 2$, from which each member comes to form their own individual attitudes towards each piece of evidence independently. Second, since it has no other resources, the group relies on its members' attitudes about E1 and about E2 to form its own attitudes about them. In the third and critical step, every epistemic agent framed in this picture obtains their own attitude $p$-that is, an attitude that results from the conjunction of the epistemic outcomes previously formed regarding $E 1$ and $E 2$. $^{7}$

This analysis shows two levels of attitudes, that is, individual attitudes and group attitudes. Both levels initially seem to differ as to the ownership of the competence that leads to the acquisition of the resulting attitude. Intuitively, according to the first step, we might be quick to accept that all the members are relatively autonomous in forming their attitudes, whilst the group is not. Likewise, the second step underlines the essential group dependence on its members to form its attitudes. However, regarding competence, it is not clear how far individual and group competence differ in terms of autonomy. In order to form its own collective attitudes, the group depends on its members' attitudes. The group comes to regard E1 as true because two on one of its members deem E1 as true. The same applies with respect to E2. Just like individuals deliberate on the reasons to believe $E 1$ and E2, groups can also be seen as deliberators in their own particular way-that is, the group deliberates considering its members' attitudes as reasons to endorse E1 and E2. Furthermore, both types of deliberating agents can be seen as similarly dependent in terms of epistemic materials. ${ }^{8}$ If so, the difference between both types of agents is the nature

\footnotetext{
7 What is remarkably distinctive of the third step is that, contrary to steps one and two, in which each agent-individual members in the first step, the group agent as a whole in the second step-forms an attitude about $E 1$ and another attitude about $E 2$, this final step depicts a situation in which the epistemic outcome results from the conjuction of the previously formed attitudes $E 1$ and E2.

8 The notion of epistemic material has to do, according to Dragos $(2021$, p. 2), with the resources on which an epistemic agent relies on ("e.g. evidence held, deliberations undertaken, inferences drawn, cognitive abilities exercised") in order to generate knowledge. Thus, on his view it is the possession of the epistemic materials that generate knowledge what delineates the difference between epistemic extension-"the idea that a subject can possess knowledge when other subjects possess some of the epistemic materials" - and epistemic autonomy-"the possession of knowledge entails possession of all the epis-
} 
of the epistemic materials that are required to produce the attitude at each level of deliberation. Thus, individuals may draw on a variety of epistemic materialsregardless of any consideration of internalist or externalist approaches about the nature of such materials - whilst the group relies, minimally, on its members' attitudes as epistemic materials in combination with a normative guidance, ${ }^{9}$ the majority rule, to form what may be dubbed as basic attitudes. This second step consequently shows that group competence bluntly depends on its members' competences to produce basic group attitudes. However, a different picture emerges in the third step. By this point in the story, as mentioned, each epistemic agent is provided with its own attitudes towards $E 1$ and E2, which are necessary in order to produce the epistemic outcome $p$ that results from the conjunction of both attitudes. Thus far, the group epistemic agent had to rely on its members' attitudes in order to form its own attitudes, but not after this moment. Just like each individual epistemic agent, the group can reach $p$, and do so on its own.

So, keeping in mind that it is $p$, and neither $E 1$ nor $E 2$, the kind of group epistemic outcome that poses a problem like the crucial disanalogy, and because in the discursive dilemma, the group brings about $p$ and does not rely straightforwardly on individual competences, but on an organisational component that affects the group just like it does in the case of its individual members-however, not depending on them-the crucial disanalogy vanishes. The group epistemic agent manifests its own competence - that is, following the rational rule of conjunction-in order to know $p$.

\subsection{Objection to the first response to the crucial disanalogy}

One might make an objection, and a very important one, indeed. Kallestrup's approach is framed within Sosa's conception of competences, according to which a complete competence is determined by three components: the seat or skill, the shape, and the situation. Which component prompts the group agent to follow the rule of conjunction instead of the rule of majority in order to arrive at $p$ ? It seems unclear whether it is part of the situation as situation involves contextual or circumstantial constraints, which is not the case. We could presume that it is the seat, but then we would have to deal with a problem that mirrors an essential component of the crucial disanalogy. Kallestrup does not deny group competence. Instead, he holds that its innermost competence, or seat, amounts to the summation of the members' innermost competences. That is why he identifies an organisational element, since «the way the group is situated or shaped dictates that it must oppose a majority attitude in order to avoid violating rationality requirements» $(2020$, p. 5244), as part

\footnotetext{
Footnote 8 (continued)

temic materials generating it". I thank the anonymous reviewer at Synthese for motivating clarification on this issue.

${ }^{9}$ It is important to exclude normative guidance as part of the epistemic materials on which the group relies. As Dragos points out, «normative properties are not epistemic materials [...] [E]pistemic materials can stand in reliability relations, but reliability properties are not epistemic materials [...] [E]pistemic materials do not include reasons themselves but our response to or engagement with reasons, that is, what we take to be reasons» $(2021$, p. 3$)$.
} 
of the group competence's shape. Accordingly, any attempt to defend an account of group competence that appeals to rationality constraints as the seat of the competence for a collective epistemic agent will be, in his opinion, doomed to failure. However, his stance might inherit part of the individualistic tendency that he is trying to cope with due to the seemingly unavoidable individualistic traits of the notion of innermost competence, or seat, itself: «the innermost [...] competence [...] in one's brain, nervous system, and body, which [one] retains even while asleep or drunk» (Sosa, 2015, p. 95; 2017, p. 191). Thus, in the game of manifesting competences as a group epistemic agent, if there is no brain, there is no gain. Any attempt to contest group competence would require capitulation.

This section has submitted Kallestrup's crucial disanalogy as the situation in which group knowledge - that is, an epistemic outcome that is not necessarily reducible to individual knowledge-is not yielded by strictly group competence, but by the summation or aggregation of individual competences. Then I have put forward an account for group competence in three steps and two levels of epistemic agency. This proposal is threatened by a significant objection in Kallestrup's view: what I allegedly take as the group's innermost competence would be actually its shape, in so far as it has to do with the organizational requirement. Additionally, this quibble is consistent with Sosa's consideration of the innermost competence as biologically hosted in the agent, something that intuitively a group agent is not able to satisfiy in terms others than mere summation. In the next section I will deepen into the notion of competence and the way group agents can manifest it in such a way that it does not reduce to individual competences.

\section{Competence and (group) know-how}

According to Sosa, competences «are dispositions of an agent to perform well» (2010a, p. 465), so they are «special cases of dispositions» (2010a, p. 466) to «succeed with a certain aim, and a competence to believe correctly is a special case of that» (2015, p. 43). Are competences and abilities, therefore, interchangeable? It is unclear. A driver may manifest her driving competence in so far as she is able to drive a car. However, she could easily be competent to drive a car despite being unable to do so. For example, a driver may have the skill to drive-and an official license that certifies it-but is incapable of doing so because she is blind drunk or the road conditions are deplorable. The distinction has to do with whether the shape and the situation components of competence are met. Thus, according to Sosa, competence and ability are not entirely interchangeable in so far as only the former is manifested as the combination of seat-that is, innermost competence-shape and situation (2010a, p. 465): one is able to drive if she has the skill of driving, but having the skill is not enough for her to exercise her ability. Similarly, «all competences are dispositions to succeed, but not all dispositions to succeed are competences» (2015, p. 100). In this case, the difference refers to the way the agent achieves success across a range of possibilities. Dispositions set mere possibilities to succeed when performing the action $\varphi$, whereas competences tie dispositions down in a reliable way to succeed when performing the action $\varphi$. This is because the agent has the 
skill to succeed when performing the action $\varphi$ and exerts it in the proper shape and in a good situation, which brings us to the core issue of what skill is in Sosa's terms:

The complete competence to drive a car on a given occasion includes factors such as the condition of the light (headlights working), one's hands being free, and so on, for various situational factors. It will include also various internal occasional factors, such as one's alcohol level, one's relevant shape at the time. Included also, finally, is a stable innermost competence, the know-how that remains even when one is poorly situated and in bad shape. Not all such inner competences are faculties but all faculties are inner competences. ${ }^{10}$ (2019, pp. 21-22)

\subsection{Skill, competence, know-how}

In the previous section, we stumbled upon a problem when attempting to defend group competence regarding some sort of psychophysical requirement for an agent to host a skill—or seat, as one of the triple-S analysis' components. Sosa's terminology stresses this conception of skill as internal to the agent, provided that it is the innermost competence that is primarily required for an agent to manifest a competent performance. However, Sosa does not provide further details about what the skill consists of. If we need to delve into it, we have to resort to other approaches. One such approach, rather close to Sosa's, is that of David Löwenstein (2017). In his Rylean analysis of know-how, he puts forward that competence, skill, and know-how are notions linked by more than a family resemblance. From the beginning, following Ryle's assumption that know-how is not merely an ability, but a special kind of ability — being equivalent to skill or competence (2017, p. 6)—, he admits that the usage of "'know-how', 'competence', and 'skill' [are] largely interchangeabl[e]» (2017, p. 7), that is, «know-how, competence and skill are one» $(2017$, p. 23$)$. The difference between these terms would then respond to a terminological variety issue, not to the presence of distinctively conceptual traits among them: each would be referring to the same phenomenon, say, intelligent practice (ibid.). Even Löwenstein himself admits the extant vicinity between his account and Sosa's, despite not delving into it (2017, p. 30). In any case, the relevance of this paper involves how his account presents skill, competence, and know-how to be equivalent.

Firstly, Löwenstein holds the claim that «knowing how to engage in an activity is knowing how to live up to the norms of that activity» (2017, p. 23). For an agent to play football, she is required to know how to play football appropriately. However, knowing the set of norms that governs the play-norms such as 'do not touch the ball with your hands, unless you are the goalkeeper or the game is stopped', for instance-does not suffice to know how to play football. Löwenstein refers to the kind of norms that govern the performance by which a football player is identified as such. Plenty of people may exhibit some abilities involved in the practice of football-kick the ball, run, jump, hit the ball with your head, and so on-but that

${ }^{10}$ My emphasis. 
is not enough. Those abilities are to be seen as general in contrast with the specific abilities that a competent football player should show in order to be accounted for as such. Moreover, those specific abilities have to do with the degree of reliability that credits how skilled the agent is in the attainment of her goal (2017, p. 28). Furthermore, fulfilling the norms in such a way that credits the agent's reliability when exhibiting the ability that is governed by those norms does not suffice to count as a competent agent either: «it requires further that one's performances are guided by the norms of the activity in question» $(2017$, p. 30$)$. That is, the agent's performance must be carried out following normative guidance that constitutes her action in such a way that corresponds with her intention to achieve success $(2017$, p. 31). The importance of normative guidance as a constitutive element for know-how-as well as competence and skill, consequently-relies on the fact that the agent's performance must not merely conform to a set of norms ${ }^{11}$ that barely grasps how to engage in the activity that the performance aims to engage in (2017, p. 36). Instead, normative guidance should be integrated into the agent's performance by an understanding of the norms that govern it (2017, p. 45). Does it mean that our football player has to understand the movements and techniques involved in her practice when training or during a match? Not necessarily. That kind of, say, modular understanding should result from a later moment, when the agent may theorise her practice by abstracting it from the practical performance. Understanding the norms that guide a competent or skilled performance has to do with the connection that the agent establishes between a set of practices and the attained goals for which that set of practices serve as a good candidate as a means to succeed. Therefore, the best way to achieve that understanding is to engage in the practices that must be understood by following the rules that govern them, to develop the agent's knowledge or competence to perform successfully. In the end, to know how to play football, it is much more appropriate for playing football rather than watching the match from the comfort of one's sofa.

I take it that the sense of integration that we infer from Löwenstein's proposal on the understanding of the norms that guide know-how in skilled agents is quite similar to Sosa's conception of the innermost seat. The main difference between the two lies in that the former does not necessarily assume any implications related to individualism. ${ }^{12}$ However, there are a couple of salient features that both approaches share. First of all, although in different ways, they are conceptualising the same phenomenon. Let us think of the driver from the triple-S analysis for competences. We could take her to be a skilled driver in the same way that we could say that she is an agent who has driving know-how, and the analysis remains the same. It is not just that she has the ability to drive a car, but she is capable of driving a car because of

\footnotetext{
11 Cfr. Löwenstein $(2017$, Ch. 1, §1.6) for clarification on the vicinity between his approach based on normative guidance and the Wittgensteinian rule-following account for language. In a nutshell, both conceptions are tantamount regarding the way action and expressions are shaped either by norms or rules that make sense in so far as they constitute the conditions of evaluation or its correctness. The cornerstone has to do with the crucial notion of practice.

12 Although Sosa admits due relevance to the social roots of knowledge (2015, Ch. 8), his organicist conception of the seat consigns it into an individual's brain and nerve system, forcing any appreciation of group competence to be done in terms of methodological individualism.
} 
her understanding of the norms that govern the practice of driving a car; an understanding that is properly integrated into her character as an agent, which leads us to the second point: both Sosa and Löwenstein's approaches assume that the way competence guides an agent's performance aiming at success involves, in turn, a way to account for a responsible action. In this case, "responsible" is tantamount to "creditable". The core element of know-how, competence and skill is normative guidance, but the way it guides the performance of the agent by means of the norms that govern the activity is understood as the responsible control that the agent has over those norms in virtue of her understanding of them (2017, p. 123). What is more: «competent actors are answerable to the norms of the activity they are engaging in, and they take responsibility for meeting them. In a word, the mark of know-how is responsible control ${ }^{13} \gg(2017$, p. 124). In short, both accounts are intermingled by the idea that understanding ${ }^{14}$ the normative guidance required for a given successful performance establishes the ownership of the competence. ${ }^{15}$

\subsection{A twofold account of group know-how}

Regarding the picture of competence as know-how, two questions follow when contemplating it in the case of group agents. How is the character of a group agent to be conceived, and how is the normative guidance that constitutes its know-how integrated into it? In what follows, I will draw on Palermos and Tollefsen's (2018) account of group know-how to address the answer in terms of non-reducibility to individual know-how. ${ }^{16}$ Their approach is divided into three parts. First, they envisage two ways in which group know-how can be devised, either as the addition or integration of the member's individual knowledge-how to establish group

\footnotetext{
13 This characterisation of responsible control parallels Sosa's metacompetences in cases of reflective knowledge, but not those involved in animal knowledge, which happen to exhibit more basic epistemic competences.

14 The requirement of understanding the norms that regulate the practice for which an agent manifests competence should prompt us to further question the nature of understanding itself, something that is beyond the scope of this paper. Some philosophers have even argued that understanding itself is knowhow (Hills, 2016) whereas others have responded against this possibility (Sullivan, 2018). Regarding what is relevant for the analysis of competence in general, and specifically the group competences approached here, I will restrict the idea of understanding to a broadly assumed common sense notion.

15 Is the notion of competence equivalent here to the one of expertise, as an anonymous reviewer for Synthese has suggested? Such reduction is objectionable, I believe, at least if we I assume Martini's $(2015,2019)$ tenet that being an expert requires social recognition. Despite the strong normative burden of the account of competence as know-how I am putting forward, it does not require such social recognition. I thank one of the referees for useful insight with respect to group expertise, a topic I intend to target in future research.

${ }^{16} \mathrm{My}$ argument against the reducibility of group competence to individual competence is independent of Palermos and Tollefsen's account of group know-how. I could thus have not resourced to it, but I think that this little detour will be helpful to attain my goal, since Palermos and Tollefsen's view provides principled motivation for the idea that group agents are entities whose activity does not reduce to the actitivity of its members.
} 
knowledge-how. Second, they provide an intellectualist ${ }^{17}$ conception of group knowhow in accordance with the additive strategy. Third, they put forward an anti-intellectualist alternative that conforms to the integrative plan. As a result, they conclude that paradigmatic cases of group know-how-such as musical collectives that play pieces together, industrial production lines or sports teams-manifest know-how that is not possessed by any of the individual members that participate in collective performances.

With respect to the first part, group know-how may be considered as the result of the aggregation of individual pieces of know-how-in the same way that summativists relate respect to belief-or the integration of a collection of individual know-how (2018, p. 115). The former is the case of an automotive production line. Each worker contributes to the final outcome - a vehicle ready to be brought to market-in their respective fields of expertise. Accordingly, everyone knows how to do their part, but no one knows how to make a car $(2018$, p. 116). It leads to the consideration of integration as the right way to understand group know-how, according to which the mere summation of individual contributions does not accurately describe in an explanatory way how a group may engage in certain activities and be responsibly creditable for its outcomes (2018, p. 117). The key element required to understand how the integration of individual know-how produces an irreducible group know-how or skill lies in the set of «complex interactions of individual members» (ibid.) which give rise to the collective properties that identify the group as the entity that deserves the attribution of the performance.

The second part of their argument envisages an intellectualist approach for group know-how in terms of joint intentionality, ${ }^{18}$ whereas the third part shows an antiintellectualist alternative that makes sense in combination with the distributed cognition hypothesis. ${ }^{19}$ The primary difference among both concerns the principle of interdependence that fixes the group as the entity subject to the attribution of knowhow. Given that intellectualism claims that saying that an agent knows how to $\varphi$ is the same as saying that an agent knows a way, $\mathrm{W}$, to do $\varphi$, the intellectualist approach to group know-how addresses interdependence between members stating that they coordinate by accepting $\mathrm{W}$ as the way to collectively do $\varphi$, so they jointly intend to follow W (2018, p. 119). However, «many times, groups of people manifest [group

\footnotetext{
17 Intellectualism about know-how is the view that knowledge-how is a species of knowledge-that (Stanley, 2011; Stanley and Williamson, 2001), responding to what is considered to be Ryle's anti-intellectualism $(1945,1949)$, which holds that knowledge-how cannot be captured by propositions. There are also positions that combine both approaches (Bengson and Moffet, 2011). In this paper, I remain neutral regarding the debates on the nature of know-how, although it may be rightfully inferred that I am much more sympathetic to anti-intellectualism of group know-how in terms similar to Dragos' (2019).

18 Joint intentionality is a phenomenon where several individuals coordinate their actions guided by a common goal; in such a way that everyone's intention assumes that the rest has the same intention (Toumela, 2000b, 2006).

19 If the hypothesis of extended mind (Clark and Chalmers, 1998) holds that there are cases in which mental states and cognitive processes extend beyond the boundaries of the skin and skull to set couple systems with objects and artifacts, the hypothesis of distributed cognition assumes that those states and processes may extend across individuals rendering collective mentality and cognition (Palermos, 2016; Theiner, 2013; Tollefsen, 2004, 2006).
} 
know-how] even though they have not previously jointly accepted a specific way, $\mathrm{W}$, which is the way that they perform their collective skill» and because «in fact, empirical evidence indicates that coordination creates commitment» (2018, p. 120). This prompts us to the alternative combination of anti-intellectualism and distributed cognition, where the principle of interdependence is set in terms of «continuous reciprocal interactions» between the members of a group (2018, p. 121). This view, based on the Dynamical Systems Theory (DTS), ${ }^{20}$ explains group know-how in terms of emergent properties, according to which:

when individual members coordinate on the basis of reciprocal interactions, they adapt mutually to each other by restricting their actions in such a way so as to reliably - that is, regularly - achieve ends that they would only luckilyif ever-bring about were they to act on their own. (2018, p. 122)

Palermos and Tollefsen's twofold account of group know-how helps understand the way the character of a group agent is shaped and how the normative guidance that governs a given performance integrates into it. Both additive and integrative conceptions for group know-how respectively parallel a way of conceiving how the principle of interdependence is established between the members that construct the group character. On the one hand, joint acceptance of $\mathrm{W}$ as the way to do $\varphi$ as a group involves, in turn, that each member commits to a norm-say, individual commitment to accept $\mathrm{W}$, as the way to jointly do $\varphi$ as a group, is necessary to do $\varphi$ as a group. In addition, each member must also know that the other members accept W, as the way to do $\varphi$ as a group jointly, and so on-which established the group as such: it is a norm - of a set of norms, depending on the case-endorsed by individual members under particular conditions that distinguishes the group in an additive way. On the other hand, mutual interdependence in the coordination of ongoing and reciprocal performances between the members of the group towards a common goal gives rise to irreducible group properties which determine the members' behaviour to preserve the group's activity as a whole. It might be the case that individual norms established in coordination initiate the group activity-in terms of a bottom-up process - however, as soon as this activity is underway, those norms take a back seat in favour of normative guidance that designates the group as the subject that must follow it in order to engage in a successful performance. Thus, the group switches from a set of individual agents to a dynamical system agent in accordance with the way each level of agency is governed by a given set of normative guidance-in terms of an up-down process.

In this section, I have shown that the innermost competence or skill, according to Sosa's triple-S analysis, that is primarily necessary for an agent to achieve success in ping through competence manifestation when engaging in the performance of $\varphi$ ing is, in Löwenstein's terms, the agent's knowledge how to $\varphi$. This view envisages an agent's knowledge-how to $\varphi$ guided by the norms that govern the performance of ping achieving success, and in such a way that her action is not merely the result

\footnotetext{
${ }^{20}$ Cfr. Palermos (2016) for a detailed presentation of the implications of DTS in the emergence of strictly collective properties that define group cognition.
} 
of adjusting her behaviour to the norms that regulate the practice she is engaging in, but also that she manifests her understanding of those norms and how they reliably lead to success. I have also introduced Palermos and Tollefsen's account of group know-how, according to which group action based on knowledge-how can be approached either as an additive phenomenon that relies on joint intentionality or an integrative one that is built as the result of ongoing mutual interactions between the members from which strictly collective properties emerge. Each approach implies a different way to take normativity as the guide to successful performance, given that the additive conception for group know-how operates with a bottom-up direction of fit-that is, individuals configuring the norms that regulate the group behaviour towards success-whilst the integrative concept does so with a top-down direction of fit-where individuals adjust their behaviour to lead the dynamics of group performance towards success.

Thus, the rather internalistic assumption of innermost competence need not be literally endorsed. Group know-how or competence might be located in «one's brain, nervous system, and body». However, the "one" addressed here is distributed among the members, from an integrative conception of group know-how, whose behaviour is determined in so far as the normative guidance that governs the activity of the group requires the members to coordinate to achieve success. Therefore, it is true that, in the game of manifesting competences as a group epistemic agent, if there is no brain, there is no gain. The key point is that a one-to-one relation between brain and competence is not necessarily required, so the normative guidance that determines an agent to be truly competent to perform a given action may be distributed across a range of individuals that act «as a body» (Gilbert, 2004, p. 100).

\section{5 (Group) competence as (group) normative status}

At the end of Sect. 3, I stressed the fact that Kallestrup's denial of group competence focuses specifically on pointing out that the group's innermost competence results from the summation of each individual's innermost competences. I have provided an alternative, according to which group innermost competence-or skill, or knowhow-is then the normative guidance it takes to perform towards success. However, he would disagree with this claim. The set of norms that regulate the group's activity, he holds, constitute an organisational element that is to be deemed as part of the shape or situation of the group, but not of its seat (2020, p. 5246). He draws on Schmitt's notion of chartered group (1994), where the "charter" comprises the «rules, norms, standards» that regulate the group activity in order to fulfil its goal (2020, p. 5242), in a way that any norms that govern the group behaviour should be part of its charter-which is shaped by the members. Consequently, as aforecited, «the way the group is situated or shaped dictates that it must oppose a majority attitude in order to avoid violating rationality requirements» (2020, p. 5244). Remembering the discursive dilemma, the decision to refuse to follow the majority rule when attaining $p$ as the conjunction of both $E 1$ and E2 is supposed to be part of the group's charter, and not a manifestation of strictly group competence. Hence, 
group innermost competence is, according to Kallestrup, nothing over and above the aggregation of the members' innermost competences.

However, nothing prevents the group from assuming the application of majority rule to produce the group attitude $p$. Since the charter is built according to the rules, norms and standards set by the individual members, they could easily agree to maintain the majority rule in their deliberation towards $p$. The crucial disanalogy unfolds as soon as we consider the group as a genuine group epistemic agent that should rationally conclude $p$ from both true pieces of evidence $E 1$ and E2. Kallestrup might even reply that switching from the majority rule to the conjunction rule as soon as the group is equipped with its own basic beliefs could be already foreseen within the group charter. Nevertheless, this objection does not change the fact that, regardless of its prior consideration by the group members, following the conjunction rule in this context determines the agent's rationality that aims at producing an epistemic outcome based on $p$.

In any case, I agree with Kallestrup in that the group's charter intends to constitute the group's capacity to perform the kind of epistemic actions that depicts the discursive dilemma. However, I disagree about the charter's scope in the constitution of the group's innermost competence. As Palermos and Tollefsen's twofold approach to group know-how shows, Kallestrup's conception of norms as determinants of the group's shape makes sense in terms of intellectualist group know-howin the sense that the group is guided by explicit norms that result from the member's joint acceptance. The same does not apply in the case of anti-intellectualist group know-how in which implicit norms guide a collective agent's performance that the members assume over the course of ongoing group performances that prompt the individuals to adjust their behaviour in accordance with the group's activity towards success. According to my account, both approaches should be considered as a reflection of the two levels of attitudes in which, on the one hand, basic group attitudes result from the majority of individual attitudes and, on the other hand, the group's attitude towards $p$ results from the conjunction of both attitudes towards E1 and E2, just as any other rational epistemic agent should do.

Therefore, we should consider group epistemic competence as the group normative status that guides towards knowledge. The notion of normative status is inspired by List and Pettit's approach to group responsibility (2011, part III). According to their view, a group agent is accountable for its actions in so far as it «faces a normatively significant choice, involving the possibility of doing something good or bad, right or wrong», «[it] has the understanding and access to evidence required for making normative judgments about the options», as well as «the control required for choosing between the options» $(2011$, p. 158). The normative status is not confined to account for the responsibility of a competent agent, since being competent is more than being merely responsible — in terms of merits or faults — of certain outcome. Being competent is also being up to certain expectations that other agents have about what one does, or those that the agent herself may have. Being competent also means acknowledging that assessments of one's performance make sense in a network of rights and duties, and being able to recognise specific values or disvalues in the practice... In this way, the normative status comprises both the normative guidance that governs the group's performance towards achieving success-that is, 
it aims to result in an epistemic outcome-and the character into which the normative guidance integrates. Both the normative guidance and the character are dynamically fixed by the practices in which the agent engages, so as to the former shapes the latter and the latter enhances the former.. ${ }^{21}$

This conception of competence makes room for and even leads to the consideration of such competent group epistemic agents as subjects that may produce reflective knowledge; to the extent that this kind of epistemic outcome results from the exercising of second-order competences. However, I admit this idea is like splitting hairs unless we accept that every piece of knowledge produced by group agents, despite it not being necessarily reducible to its member's knowledge, reverts back to the individual members. Thus, we might contemplate group competence scaffolding individual competences, and this would match the sense by which sociality represents a salient component for human beings. ${ }^{22}$

\section{Conclusion}

In this paper, I have defended an account of genuine group epistemic competence that identifies it with the group normative status that guides its performance when attempting to produce knowledge successfully. First, I suggested that the discussion may move forward by focusing on epistemic agency instead of getting stuck on the contentious issue of group belief. Then, I showed how group epistemic agency leads to discords between individual and collective attitudes as depicted in the discursive dilemma. Moreover, Kallestrup's crucial disanalogy, as presented, assumes that there is some sort of mismatch between group knowledge and group competence since group knowledge is irreducible to its members' knowledge, whereas the group competence that produces this knowledge results from the summation of the members' competences. After that, I focused on an analysis of competence comparing Sosa's triple-S analysis and Löwenstein conception of know-how as competence, concluding that both agree that competence is manifested when an agent performs an action guided by a norm or set of norms whose understanding reliably leads her to success. Having grasped this normative sense of competence, I considered it in light of Palermos and Tollefsen's dual focus on group knowledge-how. According to their approach, group know-how may be taken either from an intellectualist-joint acceptance perspective or an anti-intellectualist-dynamical view. Finally, I put forwards my response to Kallestrup, highlighting that, even though part of the process by which group competence emerges is reducible to individual competences-on the additive level that is governed by majority rule-genuine group competence is

\footnotetext{
${ }^{21}$ I am aware that the concept of normative status deserves further development. However, the main focus of this paper is the problem stressed by Kallestrup that there seems to be some form of disanalogy between group competence and individual competences. Dealing with that disanalogy is my main goal here, and an exhaustive account on what the normative status of an agent consists in will be the object of a forthcoming inquiry.

22 My statement coincides with Craig's (1990) conception of the social roots of the concept of knowledge, especially as detailed in Ch. 8 .
} 
not equally reducible to its members' competence because it is the result of the integration that takes place on a different level governed by the conjunction rule that guides any rational epistemic agent towards success-in our case, an epistemic outcome. Therefore, group epistemic competence amounts to group normative guidance when aiming at knowledge.

Acknowledgements Thanks to Jesús Navarro for helpful suggestions and comments. Previous versions of this work were presented at the IX Conference of the Spanish Society for Logic, Methodology and Philosophy of Science in Madrid, the IV SLMFCE Postgraduate Conference in San Sebastián, the VI Workshop TRACE on Intentionality \& Agency in Würzburg and the Work-in-progress talks in the University of California (Irvine). I am very grateful to the audiences in these meetings, specially to Moisés Barba, Manuel Liz, Xabier Barandiaran, Nicolas Gomont and Óscar Piedrahita. Research for this paper was supported by the Spanish MINECO (Ministerio de Economía y Competitividad) via research Grant FFI2015-67569-C2-1-P, the Spanish MICIU (Ministerio de Ciencia, Innovación y Universidades) via research Gran PGC2018-098805-B-I00 and the University of Seville through the VIPPIT-2017-IV.3 PIF program for PhD scholars. Their support is gratefully acknowledged.

Funding Open Access funding provided thanks to the CRUE-CSIC agreement with Springer Nature.

Open Access This article is licensed under a Creative Commons Attribution 4.0 International License, which permits use, sharing, adaptation, distribution and reproduction in any medium or format, as long as you give appropriate credit to the original author(s) and the source, provide a link to the Creative Commons licence, and indicate if changes were made. The images or other third party material in this article are included in the article's Creative Commons licence, unless indicated otherwise in a credit line to the material. If material is not included in the article's Creative Commons licence and your intended use is not permitted by statutory regulation or exceeds the permitted use, you will need to obtain permission directly from the copyright holder. To view a copy of this licence, visit http://creativecommons.org/licen ses/by/4.0/.

\section{References}

Bengson, J., \& Moffett, M. A. (2011). Nonpropositional intellectualism. In J. Bengson \& M. A. Moffett (Eds.), Knowing how (pp. 161-195). Oxford University Press.

Bird, A. (2010). Social knowing: The social sense of 'scientific knowledge.' Philosophical Perspectives, 24(1), 23-56.

Carter, J. A. (forthcoming). Collective (Telic) virtue epistemology. In M. Alfano, J. de Ridder \& C. Klein (Eds.), Social virtue epistemology. Routledge.

Clark, A., \& Chalmers, D. J. (1998). The extended mind. Analysis, 58(1), 7-19.

Craig, E. (1990). Knowledge and the State of Nature: An Essay in Conceptual Synthesis. Oxford University Press.

Dragos, C. (2019). Groups can know how. American Philosophical Quarterly, 56(3), 265-276.

Dragos, C. (2021). Epistemic autonomy and group knowledge. Synthese, 198, 6259-6279.

Gilbert, M. (1987). Modelling collective belief. Synthese, 73(1), 185-204.

Gilbert, M. (2002). Belief and acceptance as features of groups. ProtoSociology, 16, 35-69.

Gilbert, M. (2004). Collective epistemology. Episteme, 1(2), 95-107.

Hakli, R. (2007). On the possibility of group knowledge without belief. Social Epistemology, 21(3), 249-266.

Hills, A. (2016). Understanding why. Noûs, 49(2), 661-688.

Kallestrup, J. (2020). Group virtue epistemology. Synthese, 197, 5233-5251.

List, C., \& Pettit, P. (2004). Aggregating sets of judgments: Two impossibility results compared. Synthese, $140(1-2), 207-235$.

List, C., \& Pettit, P. (2011). Group Agency: The Possibility, Design, and Status of Corporate Agents. Oxford University Press.

Löwenstein, D. (2017). Know-how as competence. A Rylean responsibilist account. Vittorio Klostermann. 
Mathiesen, K. (2006). The epistemic features of group belief. Episteme, 2(3), 161-175.

Mathiesen, K. (2011). Can groups be epistemic agents? In H. B. Schmid, D. Sirtes, \& M. Weber (Eds.), Collective epistemology (pp. 20-23). Ontos-Velag.

Martini, C. (2015). The paradox of proof and scientific expertise. Humana Mente, 28(3-4), 1-16.

Martini, C. (2019). The epistemology of expertise. In D. Henderson, P. Graham, M. Fricker, \& N. J. L. L. Pedersen (Eds.), The Routledge Handbook of Social Epistemology (pp. 115-122). Routledge.

Meijers, A. (2002). Collective agents and cognitive attitudes. Protosociology, 16, 70-85.

Palermos, S. O., \& Pritchard, D. (2016). The distribution of epistemic agency. In P. Reider (Ed.), Social epistemology and epistemic agency: De-centralizing epistemic agency (pp. 109-126). Berlin: Rowman \& Littlefield.

Palermos, S. O. (2016). The dynamics of group cognition. Minds and Machines, 26(4), 409-440.

Palermos, S. O., \& Tollefsen, D. P. (2018). Group Know-How. In J. A. Carter, A. Clark, J. Kallestrup, S. O. Palermos, \& D. Pritchard (Eds.), Socially extended epistemology (pp. 112-131). Oxford University Press.

Pettit, P. (2007). Rationality, reasoning and group agency. Dialectica, 61(4), 495-519.

Preyer, G. (2003). What is wrong with rejectionists? In Interpretation, Sprache und das Soziale: Philosophische Artikel (Interpretaion, Language and the Social: Philosophical Articles). Frankfurt am Main.

Quinton, A. (1976). Social objects. Proceedings of the Aristotelian Society, 76, 1-27.

Ryle, G. (1945). Knowing how and knowing that. Proceedings of the Aristotelian Society, 46, 1-16.

Ryle, G. (1949). The concept of mind. The University of Chicago Press.

Schmitt, F. (1994). The justification of group beliefs. In F. Schmitt (Ed.), Socializing epistemology: The social dimensions of knowledge (pp. 257-287). Lanham, MD: Rowman and Littlefield.

Simion, M., Carter, J. A., \& Kelp, C. (2020). On behalf of knowledge first collective epistemology. In P. Silva \& L. Oliveira (Eds.), Doxastic and propositional warrant. New York: Routledge.

Sosa, E. (2009). Knowing full well: The normativity of beliefs as performances. Philosophical Studies, $142(1), 5-15$.

Sosa, E. (2010a). How competence matters in epistemology. Philosophical Perspectives, 24(1), 465-475.

Sosa, E. (2010b). Knowing full well. Princeton University Press.

Sosa, E. (2015). Judgment \& agency. Oxford University Press.

Sosa, E. (2017). Epistemology. Princeton University Press.

Sosa, E. (2019). Animal versus reflective orders of epistemic competence. In W. J. Silva-Filho \& L. Tateo (Eds.), Thinking about oneself: The place and value of reflection in philosophy and psychology (pp. 21-32). Springer.

Sosa, E. (Manuscript). Virtuous explanations. A fuller virtue theory and what it explains.

Stanley, J. (2011). Know how. Oxford University Press.

Stanley, J., \& Williamson, T. (2001). Knowing How. The Journal of Philosophy, 98(8), 411-444.

Sullivan, E. (2018). Understanding: Not know-how. Philosophical Studies, 175(1), 221-240.

Theiner, G. (2013). Onwards and upwards with the extended mind: From individual to collective epistemic action. In L. Caporael, J. Griesemer, \& W. Wimsatt (Eds.), Developing scaffolds (pp. 191208). MIT Press.

Tollefsen, D. (2003). Rejecting rejectionism. Protosociology, 18-19, 389-405.

Tollefsen, D. (2004). Collective epistemic agency. Southwest Philosophy Review, 20(1), 55-66.

Tollefsen, D. (2006). From extended mind to collective mind. Cognitive Systems Research, 7(2-3), 140-150.

Tollefsen, D. (2015). Groups as agents. Polity.

Tuomela, R. (1995). The importance of us: A philosophical study of basic social notions. Stanford University Press.

Tuomela, R. (2000a). Belief versus acceptance. Philosophical Explorations, 3(2), 122-137.

Tuomela, R. (2000b). Collective and joint intention. Mind \& Society, 1(2), 39-69.

Tuomela, R. (2006). Joint intention, we-mode and I-mode. Midwest Studies in Philosophy, 30(1), 35-58.

Tuomela, R. (2007). The philosophy of sociality: The shared point of view. Oxford University Press.

Wray, K. B. (2001). Collective belief and acceptance. Synthese, 129(3), 319-333.

Publisher's Note Springer Nature remains neutral with regard to jurisdictional claims in published maps and institutional affiliations. 